\title{
Interplay Among Hydrogen Sulfide, Nitric Oxide, Reactive Oxygen Species, and Mitochondrial DNA Oxidative Damage
}

\author{
Dandan Huang ${ }^{1 \dagger}$, Guangqin Jing ${ }^{1,2 t}$, Lili Zhang ${ }^{1}$, Changbao Chen ${ }^{1}$ and Shuhua Zhu ${ }^{1 *}$ \\ ' Food Safety Analysis and Test Engineering Technology Research Center of Shandong Province, College of Chemistry \\ and Material Science, Shandong Agricultural University, Tai'an, China, ${ }^{2}$ College of Life Sciences, State Key Laboratory \\ of Crop Genetics and Germplasm Enhancement, Nanjing Agricultural University, Nanjing, China
}

OPEN ACCESS

Edited by:

Francisco J. Corpas,

Departamento de Bioquímica,

Biología Celular y Molecular de Plantas, Estación Experimental del

Zaidin, Spain

Reviewed by:

Francisca Sevilla,

Center for Edaphology and Applied

Biology of Segura, Spanish National

Research Council, Spain

John Hancock,

University of the West of England,

United Kingdom

*Correspondence:

Shuhua Zhu

shuhua@sdau.edu.cn

${ }^{t}$ These authors have contributed

equally to this work

Specialty section:

This article was submitted to

Plant Abiotic Stress,

a section of the journal

Frontiers in Plant Science

Received: 03 May 2021

Accepted: 06 July 2021

Published: 06 August 2021

Citation:

Huang $D$, Jing $G$, Zhang $L$,

Chen C and Zhu S (2021) Interplay Among Hydrogen Sulfide, Nitric Oxide, Reactive Oxygen Species, and Mitochondrial DNA Oxidative Damage. Front. Plant Sci. 12:701681. doi: 10.3389/fp/s.2021.701681
Hydrogen sulfide $\left(\mathrm{H}_{2} \mathrm{~S}\right)$, nitric oxide $(\mathrm{NO})$, and reactive oxygen species (ROS) play essential signaling roles in cells by oxidative post-translational modification within suitable ranges of concentration. All of them contribute to the balance of redox and are involved in the DNA damage and repair pathways. However, the damage and repair pathways of mitochondrial DNA (mtDNA) are complicated, and the interactions among $\mathrm{NO}, \mathrm{H}_{2} \mathrm{~S}$, ROS, and mtDNA damage are also intricate. This article summarized the current knowledge about the metabolism of $\mathrm{H}_{2} \mathrm{~S}, \mathrm{NO}$, and $\mathrm{ROS}$ and their roles in maintaining redox balance and regulating the repair pathway of mtDNA damage in plants. The three reactive species may likely influence each other in their generation, elimination, and signaling actions, indicating a crosstalk relationship between them. In addition, $\mathrm{NO}$ and $\mathrm{H}_{2} \mathrm{~S}$ are reported to be involved in epigenetic variations by participating in various cell metabolisms, including (nuclear and mitochondrial) DNA damage and repair. Nevertheless, the research on the details of $\mathrm{NO}$ and $\mathrm{H}_{2} \mathrm{~S}$ in regulating DNA damage repair of plants is in its infancy, especially in mtDNA.

Keywords: hydrogen sulfide, nitric oxide, reactive oxygen species, mitochondrial DNA, damage repair pathway

\section{INTRODUCTION}

Hydrogen sulfide $\left(\mathrm{H}_{2} \mathrm{~S}\right)$, nitric oxide (NO), and reactive oxygen species (ROS) including superoxide anion $\left(\mathrm{O}_{2} \cdot{ }^{-}\right)$, hydroxyl radical (HO-), and hydrogen peroxide $\left(\mathrm{H}_{2} \mathrm{O}_{2}\right)$ are important intercellular signaling agents in living organisms due to their high activity, small size, and high membrane permeability (Porrini et al., 2020). For instance, $\mathrm{H}_{2} \mathrm{O}_{2}$ acts as an essential second messenger in the oxidative reactions with cysteine residues, producing the post-translationally modified proteins potent to redox signaling (Forman et al., 2010). $\mathrm{H}_{2} \mathrm{~S}$ and $\mathrm{NO}$ perform their versatile roles in plants primarily due to the protein $S$-nitrosation and persulfidation, respectively, which are oxidative post-translational modifications of cysteine residues (Filipovic and Jovanovic, 2017; Porrini et al., 2020). NO can also react with $\mathrm{O}_{2} \cdot{ }^{-}$and $\mathrm{H}_{2} \mathrm{~S}$ to produce signaling molecules peroxynitrite and $S$-nitrothiols, respectively (Hancock, 2017). In plants, all these endogenously generated reactive species appear to play multiple roles in many crucial physiological and biochemical processes (Figure 1), including modulating seed germination, maintaining plant growth and development, regulating plant senescence and fruit ripening, and improving the tolerance to biotic or abiotic stresses (Corpas, 2019b; Huang et al., 2019). 


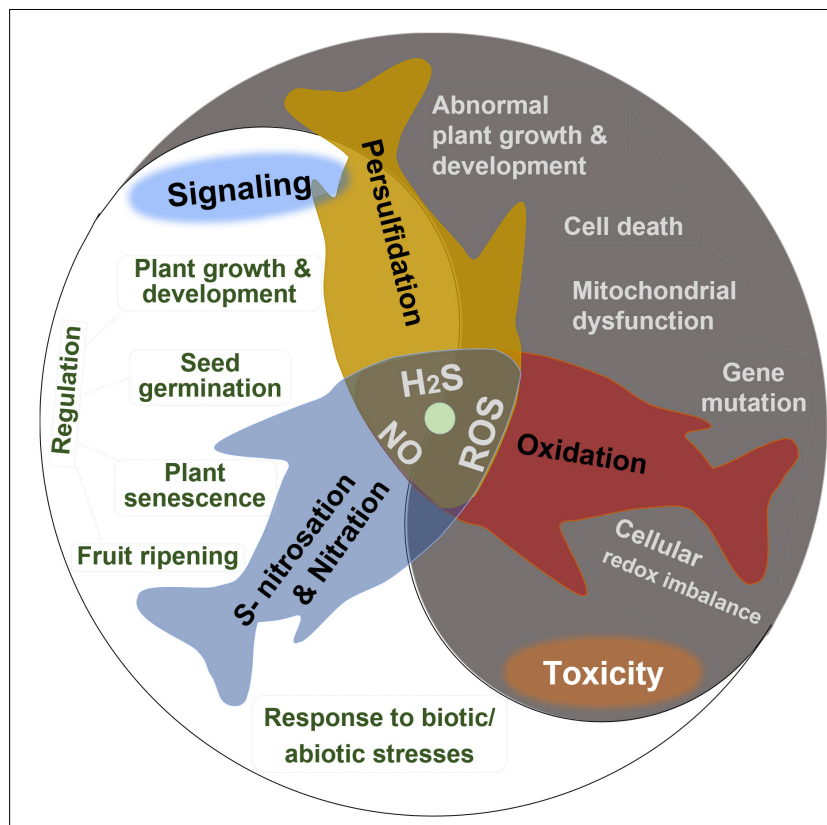

FIGURE 1 | Summary of the dual bioactive role of reactive oxygen species (ROS), hydrogen sulfide $\left(\mathrm{H}_{2} \mathrm{~S}\right)$, and nitric oxide (NO) in plants. All of them act as signaling agents by post-translational modification in many crucial physiological and biochemical processes but are toxic in excessive levels.

The positive effects of $\mathrm{H}_{2} \mathrm{~S}, \mathrm{NO}$, and ROS depend on their proper concentrations; if not, the toxic effects show up. So, learning the exact boundary between the physiological and toxicological concentration of endogenous ROS, NO, and $\mathrm{H}_{2} \mathrm{~S}$ contents is essential. The in vivo concentration of these three active substances showed great differences when measured via different methods. The entire $\mathrm{H}_{2} \mathrm{~S}$ content ranges from 0.010 to $0.199 \mu \mathrm{mol} \mathrm{g}^{-1} \mathrm{FW}$ by the methylene blue method. Using the electrode method, the $\mathrm{H}_{2} \mathrm{~S}$ content showed a wider range, from 0.177 to $0.708 \mu \mathrm{mol} \mathrm{g}^{-1} \mathrm{FW}$ (Jin et al., 2018). Low-level $\mathrm{H}_{2} \mathrm{~S}$ and NO have acted as signaling molecules to delay the senescence of postharvest fruits and ameliorate cold stress injuries (Geng et al., 2019; Wang et al., 2021). When their concentrations reach higher levels than normal, stresses are sensed. The excessive reactive species constantly attack biomolecules, leading to severe or even irreversible oxidative modification, such as lipid peroxidation, protein oxidation, and oxidative DNA damage, which can induce membrane damage, functional changes, strand breaks, and even lead to cell death (Trachootham et al., 2008). The uncontrolled increasing level of ROS generated in plants under stress conditions often induces abnormal growth or even death of plants (Huang et al., 2019). Excessive $\mathrm{H}_{2} \mathrm{~S}$ negatively affects the mitochondrial respiratory chain with the inhibition of cytochrome $c$ oxidase by redox-reacting with the metal center (Filipovic et al., 2018).

Therefore, given the dual role depending on concentrations, maintaining the balance between production and elimination of $\mathrm{H}_{2} \mathrm{~S}$, NO, and ROS in plants is pivotal to continue their positive roles. The abiotic stresses elevate ROS production and may concomitantly accumulate endogenous $\mathrm{NO}$ and $\mathrm{H}_{2} \mathrm{~S}$, which can reduce oxidative stress by promoting antioxidative defenses to scavenge ROS (Bhuyan et al., 2020). Moreover, excessive ROS may convert $\mathrm{NO}$ to $\mathrm{ONOO}^{-}$, which triggers nitrooxidative stress (Corpas and Barroso, 2013), leading to protein tyrosine nitration. $\mathrm{H}_{2} \mathrm{~S}$ can increase the endogenous $\mathrm{NO}$ level (Amooaghaie et al., 2017; Corpas et al., 2019), and NO can likewise induce the accumulation of endogenous $\mathrm{H}_{2} \mathrm{~S}$ in plants (Peng et al., 2016). Taken together, as bioactive species, ROS, NO, and $\mathrm{H}_{2} \mathrm{~S}$ independently or collaboratively act with each other to participate in the regulation of diverse cellular processes. In this study, we summarized the production and elimination of ROS, $\mathrm{NO}$, and $\mathrm{H}_{2} \mathrm{~S}$ in plants and their roles in cellular redox balance and DNA damage and repair, attempting to describe the interplay between these reactive species from their metabolism to their regulatory performance in responding to stresses. On top of that, we described the prospects of $\mathrm{NO}, \mathrm{H}_{2} \mathrm{~S}$, and ROS in the field of mitochondria and mitochondrial DNA (mtDNA) in plants.

\section{METABOLISM OF ROS, NO, AND $\mathrm{H}_{2} \mathrm{~S}$ IN PLANTS}

Generally, ROS can be produced in the cellular compartments of plants from aerobic metabolism, including respiration and photosynthesis, and regulate the life processes of plants, exhibiting its positive or toxic roles under normal or abnormal conditions (Jiao et al., 2014; Yu et al., 2017; Waszczak et al., 2018). In higher plants, ROS can be produced in chloroplasts, mitochondria, cell membranes, and peroxisomes, among which the chloroplasts and mitochondria are the main production sites and produce ROS primarily through the electron transport chain (ETC) (Fluhr, 2009). In mitochondria of plants, the ETC includes the cytochrome pathway and alternative pathway, but $\mathrm{H}_{2} \mathrm{O}_{2}$ or $\mathrm{O}_{2}{ }^{-}$is not the end product of the reduction of oxygen in the alternate pathway (Moore and Siedow, 1991). The respiratory complexes $\mathrm{I}$ and III are the major sites of $\mathrm{O}_{2} \cdot-$ production in mitochondria. $\mathrm{O}_{2}{ }^{-}$can be dismutated spontaneously or catalyzed by mitochondrial manganese-superoxide dismutase (Mn-SOD) into $\mathrm{H}_{2} \mathrm{O}_{2}$, which is then detoxified by peroxiredoxin (Prx), glutathione peroxidase (GPX), and ascorbate peroxidase (APX) of the ascorbate-glutathione cycle in plant mitochondria (Jimenez et al., 1997; Chew et al., 2003). $\mathrm{H}_{2} \mathrm{O}_{2}$ can be converted into a hydroxy radical $(\mathrm{HO})$ when reacted with redox-active transition metals. Additional endogenous sources of ROS comprise the membrane-associated NAD $(\mathrm{P}) \mathrm{H}$ oxidase (NOX) and xanthine oxidase (XO) (Trachootham et al., 2008). Studies showed that NOXs could regulate plant cell expansion by producing ROS, and the knockout of RHD2, an NADPH oxidase, resulted in decreased ROS content and short root hairs and stunted roots in Arabidopsis (Foreman et al., 2003). Besides, NADPH-mediated ROS generation was found to be related to the stomatal closing (Kwak et al., 2003), further indicating the important functions of ROS in plant growth and development. Food extracts such as hesperetin could inhibit the activity of $\mathrm{XO}$, reducing oxidative stress caused by ROS (Dew et al., 2005). ROS can be scavenged via enzymatic antioxidant systems mainly including SOD, catalase 
(CAT), peroxidase (POD), APX, GPX, monodehydroascorbate reductase (MDHAR), dehydroascorbate reductase (DHAR), and glutathione reductase (GR), and nonenzymatic antioxidants, including $\mathrm{NAD}(\mathrm{P}) \mathrm{H}$, glutathione (GSH), ascorbic acid (AsA), and flavonoids, which is well summarized by Huang et al. (2019).

Nitric oxide, as a small and redox-active molecule, plays versatile roles in the physiological and biochemical processes in plants (Brouquisse, 2019; Gupta et al., 2020). Dynamic monitoring of $\mathrm{NO}$ in the imbibed seeds showed that the amount of NO released reached a peak at $3 \mathrm{~h}$; moreover, increased NO release (5 $\left.\mathrm{nmol} \mathrm{min} \mathrm{m}^{-1} \mathrm{~g}^{-1} \mathrm{DW}\right)$ observed in Arabidopsis seeds treated with sodium nitroprusside (SNP, an NO donor) enhanced seed germination (Liu et al., 2009). For a long time, researchers dedicated themselves to clone nitric oxide synthase (NOS) from plants to figure out the biosynthetic pathway of NO but failed. Reports showed that NO can be produced from nitrite through the nonenzymatic reduction and the catalysis by nitrite reductase, nitrate reductase, or molybdoenzymes and from an oxidative route with NOS-like activity in plants (Astier et al., 2018; Kolbert et al., 2019). The mitochondrial electron transport chain (mETC) also involves the production of NO from nitrite (Alber et al., 2017; Gupta et al., 2018). Complex I (NADH: ubiquinone oxidoreductase), cooperating with rotenone-insensitive $\mathrm{NAD}(\mathrm{P}) \mathrm{H}$ dehydrogenases, regulates the production of NO under hypoxia; Complex II (succinate: ubiquinone oxidoreductase) contains $\mathrm{Fe}-\mathrm{S}$ centers which can be inhibited by NO, regulating the generation of ROS; Complex III (ubiquinol: cytochrome $c$ oxidoreductase) transfers an electron to nitrite to generate NO; Complex IV (cytochrome $c$ oxidase) also contributes to the interconversion between nitrite and $\mathrm{NO}$ and the generation of ATP via the phytoglobin-NO cycle (Alber et al., 2017; Gupta et al., 2018). Complex V ( $\mathrm{F}_{1} \mathrm{~F}_{\mathrm{O}}$-ATPase) synthesizes most of the ATP and provides energy to living cells. Tyrosine nitration caused by $\mathrm{NO}$ can inhibit the $\mathrm{F}_{1} \mathrm{~F}_{\mathrm{O}}$-ATPase activity (Nesci et al., 2017). Many studies have shown that excess NO can inhibit oxygen metabolism by the cytochrome pathway; however, the inhibition of oxygen metabolism in the alternative pathway is very weak (Millar and Day, 1996). The cDNA microarray and Northern analysis evidenced that appropriate NO levels could induce the transcription of alternative oxidase $(A O X)$ in Arabidopsis cells (Huang et al., 2002). Meanwhile, the activation of NO on $A O X$ transcription was also observed in tobacco (Ederli et al., 2006), and the relationship between NO and AOX was further explored by Cvetkovska and Vanlerberghe (2012) by using the transgenic material of $A O X$ in tobacco, and a preliminary conclusion was drawn: AOX respiration acts to reduce the generation of ROS and reactive nitrogen species (RNS) in plant mitochondria by dampening the leak of a single electron from the ETC to $\mathrm{O}_{2}$ or nitrite. Excess $\mathrm{NO}$ may also trigger the $S$-nitrosation of complex I and other proteins.

Hydrogen sulfide has been identified as a new endogenous player in plants, and it is a mitochondrial substrate or a poison to mitochondria at low or high concentrations, respectively (Guo et al., 2016). The role of $\mathrm{H}_{2} \mathrm{~S}$ in cells has long been a matter of controversy: Hancock and Whiteman (2014) categorize $\mathrm{H}_{2} \mathrm{~S}$ as a referee, one for its role in responding to stresses by interacting with $\mathrm{NO}$ and ROS metabolism passively and another for the lack of a dedicated pathway in which $\mathrm{H}_{2} \mathrm{~S}$ responds to such stresses. $\mathrm{H}_{2} \mathrm{~S}$ in plants is more often considered to be a signaling molecule for its important and irreplaceable function in various physiological processes of plant cells. In plants, the diversity of sources ensured the needed supplement of $\mathrm{H}_{2} \mathrm{~S} . \mathrm{H}_{2} \mathrm{~S}$ comes from the environment and the endogenous generation via enzymatic and nonenzymatic pathways in chloroplasts, mitochondria, and cytosols. Plants actively take up $\mathrm{H}_{2} \mathrm{~S}$ in the atmosphere via the foliage, which can be converted into GSH in cells, leading to the increased accumulation of thiol, consequently (Ausma and De Kok, 2019). $\mathrm{H}_{2} \mathrm{~S}$ can be generated in plants through various biosynthetic pathways, such as sulfite reductase ( $\mathrm{SiR}$ ): converting sulfite to $\mathrm{H}_{2} \mathrm{~S}$, cysteine desulfhydrase (CD): converting cysteine to pyruvate and $\mathrm{H}_{2} \mathrm{~S}$, and cysteine synthase (CS): converting L-cysteine to O-acetyl-L-serine and $\mathrm{H}_{2} \mathrm{~S}$. Mitochondrial $\beta$-cyanoalanine synthase $(\beta$-CAS) catalyzes the conversion of cyanide and L-cysteine to $\beta$-cyanoalanine producing $\mathrm{H}_{2} \mathrm{~S}$ (Gotor et al., 2019). Nitrogenase Fe-S clusters also contribute to the generation of $\mathrm{H}_{2} \mathrm{~S}$ from L-cysteine in mitochondria (Liu et al., 2015). $\mathrm{H}_{2} \mathrm{~S}$ can be detoxicated by sulfide: quinone oxidoreductase (SQR), superoxide dismutase (SOD), or $\mathrm{O}$-acetylserine(thiol)lyase C (OAS-TL C). SQR converts $\mathrm{H}_{2} \mathrm{~S}$ to persulfides, which can be transferred into the conversion between GSH and glutathione persulfide (GSSH), and the sulfur is then sequentially oxidized by the mitochondrial sulfur dioxygenase ETHE1 to sulfite and by sulfite oxidase (SO) to sulfate or thiosulfate regenerated by thiosulfate sulfurtransferase (TST), transferring sulfur from GSSH to sulfite (Olson, 2018). Mitochondrial Mn-SOD also catalyzes the oxidation of $\mathrm{H}_{2} \mathrm{~S}$ into polysulfides (D’Imprima et al., 2016; Olson, 2018). OAS-TL C could transfer sulfide to O-acetylserine to form cysteine in the mitochondria of Arabidopsis (Birke et al., 2015).

\section{$\mathrm{H}_{2} \mathrm{~S}$, NO, AND REDOX BALANCE IN PLANTS}

Reactive oxygen species, reactive sulfur species (RSS), and RNS burst in plants under both biotic and abiotic stress could cause the plants to responds to abnormal conditions (Jia et al., 2016; Yu et al., 2017; Corpas, 2019a; Hancock, 2019) and participate in the ripening of fruit (Muñoz-Vargas et al., 2020). During the ripening and stress response processes, ROS accumulation is ubiquitous in several sub-organelles of the cell, such as mitochondria, chloroplasts, and peroxisomes. Accompanied with this, intracellular RNS, such as NO, also increased, which alleviated oxidative damage caused by excessive accumulation of ROS via the intracellular antioxidant pathway (Zhu et al., 2014). The increasing intracellular NO could also delay the maturation and senescence of fruits by regulating ethylene biosynthesis and the ethylene signal transduction pathway and by affecting the genes of cell wall degrading enzymes (Lin et al., 2020). Mutation of SILCD1, the $\mathrm{H}_{2} \mathrm{~S}$-producing enzyme, lowered the $\mathrm{H}_{2} \mathrm{~S}$ content and accelerated fruit ripening in tomato, while exogenous $\mathrm{H}_{2} \mathrm{~S}$ treatment in unripe fruits of tomato suppressed the expression of the ripening-related gene, suggesting that 
$\mathrm{H}_{2} \mathrm{~S}$ is involved in the regulation of fruit ripening ( $\mathrm{Hu}$ et al., 2020).

Pretreatment with exogenous $\mathrm{H}_{2} \mathrm{~S}$ could upregulate the activities of antioxidant enzymes to remove excessive ROS and reduce oxidative damage in Chinese cabbage roots, therefore alleviating the growth inhibition caused by cadmium (Zhang et al., 2015). Exogenous $\mathrm{H}_{2} \mathrm{~S}$ could decrease mitochondrial permeability transition and ROS contents but increase mitochondrial membrane fluidity, mitochondrial membrane potential, and antioxidative enzyme activities in roots of Malus hupehensis under $\mathrm{NaCl}$ stress (Wei et al., 2019). The salinityinduced augmentation of $\mathrm{H}_{2} \mathrm{~S}$ and $\mathrm{NO}$ levels is associated with the increase of L-cysteine and L-arginine and the induction of the enzymes involved in the biosynthesis of $\mathrm{H}_{2} \mathrm{~S}$ or $\mathrm{NO}$ (da Silva et al., 2017). Sodium hydrosulfide (NaHS) alleviates oxidative damage by increasing the activities of SOD, CAT, POD, and APX, promoting the transcript level of CSNMAPK and the accumulation of endogenous NO through the MAPK/NO signal pathway in cucumber against excess nitrate stress (Qi et al., 2019). The enhanced accumulation of GSH induced by $\mathrm{H}_{2} \mathrm{~S}$ alters the redox of the cell, which may consequently increase the tolerance of plants to environmental stress (Noctor et al., 2012).

Both NaHS and SNP can increase the endogenous NO level and enhance the antioxidant enzyme activities in Bermuda grass under lead stress (Amooaghaie et al., 2017). Exogenous NaHS increases the content of endogenous $\mathrm{H}_{2} \mathrm{~S}$ and the activity of L-cysteine desulfhydrases (L-CD) in tomatoes under nitrate stress and induces the synthesis of NO through nitrate reductase and not NOS (Liang et al., 2018). Exogenous SNP could also induce the accumulation of endogenous $\mathrm{H}_{2} \mathrm{~S}$ by increasing the activities of L-CD, OAS-TL, and $\beta$-CAS, and exogenous NaHS enhances the NO-induced hypoxia tolerance in maize (Peng et al., 2016). However, exogenous NO decreases the activities of L-/D-CD, OAS-TL, and SiR and increases the activity of $\beta$-CAS, leading to a decrease in the contents of endogenous $\mathrm{H}_{2} \mathrm{~S}$, cysteine, and sulfite in peaches during cold storage (Geng et al., 2019). Treatment of exogenous $\mathrm{H}_{2} \mathrm{~S}$ at high concentration triggered the activation of MPK6, consequently inducing the production of NO, and in turn, the exogenous $\mathrm{H}_{2} \mathrm{~S}$-mediated changes in auxin distribution were regulated by NO produced here, resulting in the inhibition of the primary root growth in Arabidopsis (Zhang P. et al., 2017). cPTIO (as an NO scavenger) and sodium tungstate (as an inhibitor of nitrate reductase) increase the $\mathrm{H}_{2} \mathrm{~S}$ content by sustaining the activities of L-/D-CDs, OAS-TL, and SiR; L-NAME (as an inhibitor of NOS-like activity) improves the $\mathrm{H}_{2} \mathrm{~S}$ content mainly by maintaining the D-CD activity, suggesting that there would be different interactions between the NO biosynthesis and the $\mathrm{H}_{2} \mathrm{~S}$ metabolism (Geng et al., 2019). Also, hypotaurine (as the specific scavenger of $\mathrm{H}_{2} \mathrm{~S}$ ) reduces the endogenous $\mathrm{H}_{2} \mathrm{~S}$ levels and reverses the responses induced by NaHS but cannot completely reverse the responses induced by SNP; while cPTIO quenches the effects of both NaHS and SNP on Pb tolerance of Sesamum (Amooaghaie et al., 2017). These results also suggest that there would be a two-sided link between the signal molecules of $\mathrm{H}_{2} \mathrm{~S}$ and $\mathrm{NO}$ (Figure 2) and that $\mathrm{H}_{2} \mathrm{~S}$ increases the NO production and, subsequently, $\mathrm{NO}$ tightly regulates feedback of the $\mathrm{H}_{2} \mathrm{~S}$ biosynthesis (Amooaghaie et al., 2017). The complicated

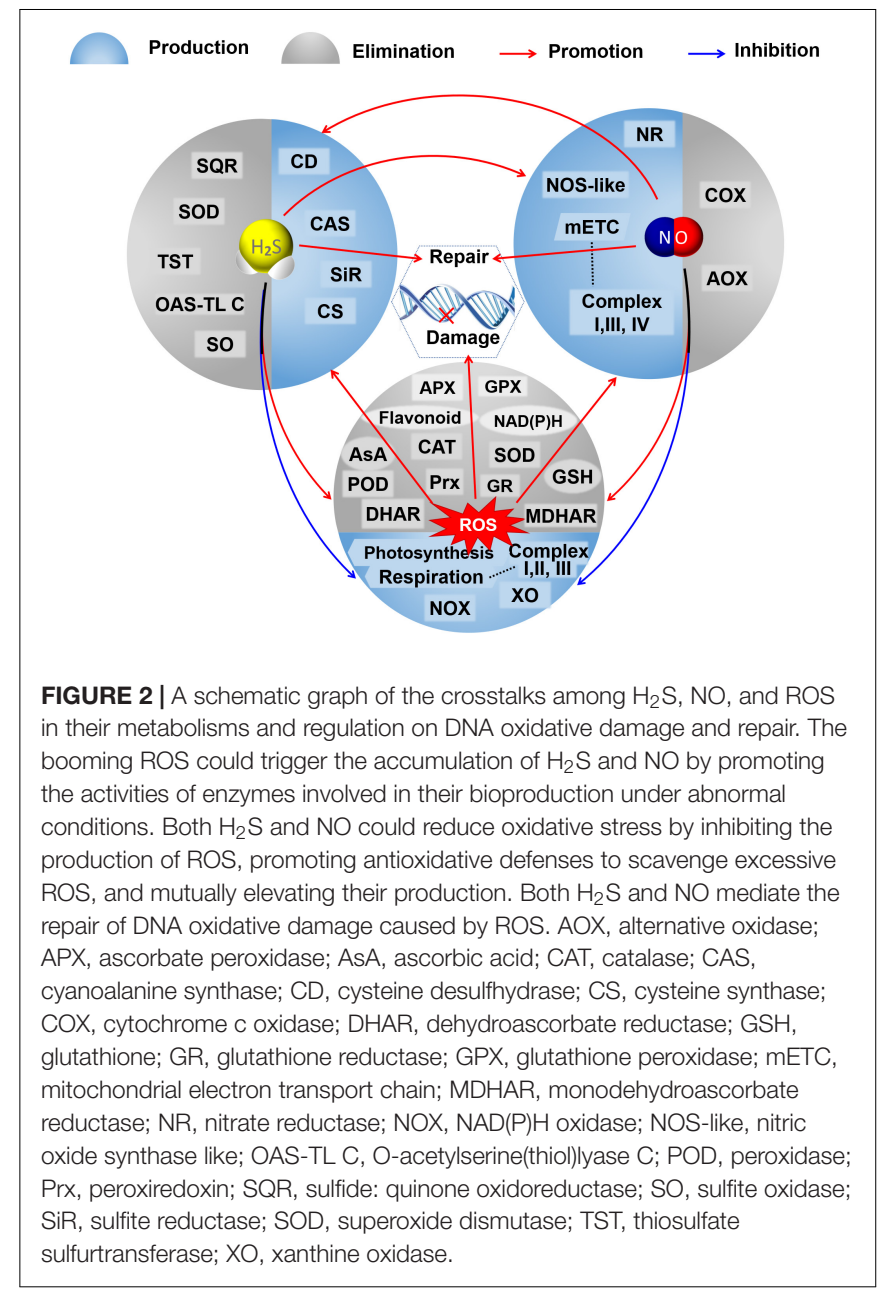

relationships between the $\mathrm{H}_{2} \mathrm{~S}$ and the $\mathrm{NO}$ signaling cascade might depend on their respective concentrations, the different physiological and biochemical processes, different tissues and organs, and different species of plants under normal conditions or varied conditions of abiotic stress.

The current knowledge of the regulation by $\mathrm{H}_{2} \mathrm{~S}, \mathrm{NO}$, and ROS on plant defense against abiotic stress has been well reviewed (Bhuyan et al., 2020). Interactions among $\mathrm{H}_{2} \mathrm{~S}, \mathrm{NO}$, and ROS in mitochondria, cytoplasm, and chloroplast influenced the responses of the plant to abiotic stresses and the processes of ripening and senescence (Hancock and Whiteman, 2016; Zhang P. et al., 2017; Muñoz-Vargas et al., 2018; GonzálezGordo et al., 2020). To survive, plants try to maintain a proper cellular redox balance. However, the interactions among $\mathrm{H}_{2} \mathrm{~S}$, $\mathrm{NO}$, and redox balance are still not precise and need to be further improvised.

\section{MITOCHONDRIAL DNA OXIDATIVE DAMAGE AND REPAIR IN PLANTS}

The mitochondrion has its own DNA (mtDNA), which is highly variable in size and structure depending on the species. The 
mtDNA in plants is larger than human mtDNA, typically around 200-400 kb, which can be much bigger, reaching up to $11.3 \mathrm{Mb}$, and can encode about 20 additional genes in comparison to animals (Chevigny et al., 2020). The mtDNA is located near the electron transfer chain and encodes many critical proteins for the assembly and activity of the mitochondrial respiratory complexes (Alencar et al., 2019). The mtDNA is a circular molecule and is packed by proteins including prohibitins, the ATPase family AAA domain-containing protein 3 (ATAD3), mitochondrial transcription factor A (TFAM), DNA polymerase gamma, catalytic subunit (POLG), etc., forming a nucleoid that uniformly distributes within the mitochondrial matrix, which is essential for mitochondrial functions.

Proper levels of biological oxidations originating in mitochondria fulfill the beneficial roles in redox homeostasis, while excessive oxidants overwhelming the antioxidant defenses cause redox imbalance, disrupt mitochondrial function, and lead to dysfunction, aging, and cell death (Piantadosi, 2020). ROS (especially HO.) have a single electron and are prone to nucleophilic attack on DNA molecules, resulting in changes such as modification of DNA sequences, causing pairing and coding errors during DNA replication, and gene mutations (Poetsch, 2020). The DNA oxidative damage includes base modifications, abasic sites, and strand breaks (Gonzalez-Hunt et al., 2018). The stability of the mtDNA is essential for proper mitochondrial function. However, the mtDNA can more easily be injured by ROS on account of its proximity to the site of ROS generation and the impotent mtDNA repair (Trachootham et al., 2008). For example, exogenous $\mathrm{H}_{2} \mathrm{O}_{2}$ treatment resulted in the oxidation of Pol $\gamma$ and reduction in exonuclease activity, which in turn converted the high fidelity Pol $\gamma$ into an editingdeficient polymerase, leading to an increase in mtDNA mutations (Anderson et al., 2019).

The preservation of DNA integrity is necessary for ensuring unperturbed transcription (Lans et al., 2019). Unlike other cell macromolecules, damaged DNA cannot be replaced and can only maintain its integrity through direct damage reversal, mismatch repair (MMR), nucleotide excision repair (NER), base excision repair (BER), and recombination pathways [targeting DNA damages of double-strand breaks (DSBs) and singlestrand gaps (SSGs)] (Chevigny et al., 2020). Direct damage reversal is the simplest way with the activities of photolyase, alkyltransferase, and dioxygenase to restore the damaged base of cellar DNA without excision of the base or the phosphodiester backbone (Yi and He, 2013). For example, photolyase could use visible light to transfer electrons from $\mathrm{FADH}^{-}$to cyclobutane pyrimidine dimers (CPDs), a major UV-induced lesion in DNA in plants, resulting in CPD splitting (Zhang M. et al., 2017); alkyltransferase could repair $\mathrm{O}(6)$-methylguanine in DNA by transferring the methyl group (Pegg, 2000); and dioxygenase could also demethylate DNA methylation by oxidizing 5methylcytosine (5-meC) (Wu et al., 2018).

The non-canonical base pairing and insertion-deletion loops can be repaired via the MMR pathway, which is usually associated with the replication machinery in the nuclear matrix but is unclear in the mitochondria (Chevigny et al., 2020). The NER pathway repairs the lesions of DNA caused by
UV radiation by removing DNA-binding lesions and adducts, creating a gap, which will be filled by synthesizing damage-free DNA by polymerases to finally be ligated by sealing the nick (Kobaisi et al., 2019).

However, NER and MMR pathways do not exist in plant mitochondria (Van Houten et al., 2018; Wynn et al., 2020), and BER is the primary repair pathway for mtDNA oxidative damage (Ferrando et al., 2019). The deaminations, oxidations, alkylations, and single-strand breaks of DNA can be repaired via the BER pathway (Alencar et al., 2019), the glycolytic excision of the damaged base activated the BER, and the diversity of DNA glycosylases that specifically recognize different types of lesions determined the efficiency of BER (Krokan et al., 1997). Uracil-DNA glycosylase (UNG) from Arabidopsis is imported into the mitochondria (Boesch et al., 2009), combined with UNG found in maize and potato (Bensen and Warner, 1987; Ferrando et al., 2019), indicating that UNG is present in the mitochondria of plants and contributes to the repair of the mtDNA. In addition, double-strand break repair (DSBR) is suggested to be a general system of repairing many DNA lesions in plant mitochondria (Wynn et al., 2020). Among the four distinct DSBR pathways, including non-homologous DNA end joining (NHEJ), alternate end joining (a-EJ), homologous recombination (HR), and single-strand annealing (SSA), HR is considered as the primary DNA repair pathway in the mitochondria of plants (Chevigny et al., 2020).

\section{$\mathrm{H}_{2}$ S AND NO AFFECT mtDNA OXIDATIVE DAMAGE}

Oxidative damage of nuclear DNA and mtDNA can be induced by the excessive accumulation of ROS in plant cells, which could also cause epigenetic variations in plants, such as DNA methylation/demethylation (Katsuya-Gaviria et al., 2020; Nagaraja et al., 2021) and histone modifications (Zheng et al., 2021) influencing plant development and growth. DNA damage caused by ROS could trigger the nuclear redox network and affect DNA metabolism through redox-dependent regulatory mechanisms comprising redox buffering and posttranslational modifications, such as the thiol-disulfide switch, glutathionylation, and S-nitrosation (Cimini et al., 2019). Recently, it has been found that ROS can function as catalysts of DNA methylation ( $\mathrm{Wu}$ and Ni, 2015; Teng et al., 2018). As mentioned before, both $\mathrm{NO}$ and $\mathrm{H}_{2} \mathrm{~S}$ within moderate concentration could maintain redox balance by involving the ROS metabolism and the antioxidant system, scavenging excess ROS and, thus, mitigating the oxidative DNA damage; moreover, $\mathrm{NO}$ and $\mathrm{H}_{2} \mathrm{~S}$ were verified to regulate the expression and posttranscriptional modification of proteins related to DNA oxidative damage and repair (Figure 2).

Nitric oxide and $\mathrm{H}_{2} \mathrm{~S}$ can be involved in the DNA oxidative damage via epigenetic modification. The most extensively studied and characterized epigenetic modification of DNA is the methylation of cytosine (C) with an addition of a methyl group to carbon 5 (C5) of the pyrimidine ring (5meC) (Law and Jacobsen, 2009; Michalak et al., 2013). The 
methylation state of plant genomic DNA will change into the hypermethylation/hypomethylation form to affect the structure of chromatin and DNA conformation, DNA stability, and the way DNA interacts with proteins, as well as the expression of related genes under abiotic stress (Liu et al., 2017; Zhang et al., 2018). Besides, DNA demethylation, mediated by teneleven translocation dioxygenase (TET) 3, is reported to be crucial for efficient repair of DNA damage (Jiang et al., 2017). Studies on the roles of $\mathrm{NO}$ and $\mathrm{H}_{2} \mathrm{~S}$ in DNA/mtDNA oxidative damage are more advanced in mammals. For example, mtDNA haplogroup J, which was proved to be associated with several multifactorial diseases and aging, modulates NO production (Fernández-Moreno et al., 2011), and people carrying the mtDNA haplogroup J show lower mitochondrial oxidative damage (Martínez-Redondo et al., 2010); reduction of NO and DNA/RNA oxidation products were observed in patients with systemic lupus erythematosus, and NOx levels and DNA/RNA oxidation products were inversely and independently associated (Iriyoda et al., 2017), all of these indicating that $\mathrm{NO}$ is associated with DNA oxidative damage. NO takes part in the regulation of DNA methylation, although likely to be genotoxic at high concentrations. Excessive NO can cause the deamination of cytosine to uracil in single-stranded DNA cytosine residues, resulting in DNA/mtDNA damage, histone deamination (Merchant et al., 1996). As an NO donor, SNP at high concentration inhibits the growth of rice seedlings, which is associated with hypomethylation at the $\mathrm{CHG}$ sites $(\mathrm{H}=\mathrm{A}$, $\mathrm{C}$, or $\mathrm{T}$ ) of genomic DNA and the transcriptional activation of genes and transposable elements, and the DNA methylation caused by SNP is inherited by the next generation (Ou et al., 2015). Proper concentration of exogenous NO mitigates the increase of genomic template instability, DNA methylation, and retrotransposon polymorphism caused by copper stress by increasing the efficiency of the antioxidative system in lettuce (Yagci et al., 2019). Studies in smooth muscle cells and aorta tissues of mice found that a sufficient level of $\mathrm{H}_{2} \mathrm{~S}$ was able to inhibit TFAM promoter methylation and maintain the mtDNA copy number (Ou et al., 2015). Methyl in trans-methylation reactions are tightly coupled with the activated methyl cycle, a crucial contributor to DNA and RNA methylation in stress-exposed plants (Rahikainen et al., 2018). As a donor of the methyl in trans-methylation reactions, $S$-adenosyll-methionine (SAM) was associated with the production of $\mathrm{H}_{2} \mathrm{~S}$ (Eto and Kimura, 2002). NO can regulate enzymes such as S-adenosylhomocysteine hydrolase/homologous gene silencing 1 , methionine synthase, and S-adenosyl methionine synthase/methionine adenosyltransferases in SAM synthesis via $S$-nitrosation and tyrosine nitration (Lindermayr et al., 2005; Kumar et al., 2020), indicating the crosstalk between $\mathrm{H}_{2} \mathrm{~S}$ and NO in regulating DNA methylation/demethylation.

On the other hand, $\mathrm{NO}$ and $\mathrm{H}_{2} \mathrm{~S}$ could participate in the DNA/mtDNA damage (repair) via post-transcriptional modification of proteins. NO-mediated increase in DNAdependent protein kinase catalytic subunit (DNA-PKcs), a key double-strand DNA break repair enzyme involved in nonhomologous end-joining, demonstrated the presence of a new and highly effective NO-mediated mechanism for DNA repair through $S$-nitrosation and transcriptional regulation (Xu et al., 2000). NO also modifies histone methylation by regulating protein arginine methyltransferase activity by $S$-nitrosation, upregulating the expression of the gene encoding lysine methyltransferase, which is the predominant mechanism for transduction of NO bioactivity (Hussain et al., 2016; Blanc and Richard, 2017). Similarly, the NO donor treatment resulted in tyrosine nitration and inhibition of its activity possibly through $S$-nitrosation, which involved DNA repair (Jones et al., 2009). The redox modifications, such as the $S$-nitrosation caused by NO, may inhibit histone deacetylases (HDAC 2C and 2B) and modulate histone acetylation in Arabidopsis (Chaki et al., 2015; Mengel et al., 2017). Histones, acetyltransferases, and methyltransferases are the targets for persulfidation (Aroca et al., 2018), suggesting that $\mathrm{H}_{2} \mathrm{~S}$ can also participate in DNA repair like NO. Exogenous SNP and $S$-nitrosoglutathione (GSNO), as NO donors, cause the $S$-nitrosation of Cys49 and Cys53, promoting a conformational change in the secondary structure in proteins of the AtMYB30 transcription factor and inhibiting the DNA binding ability of R2R3-MYB2 from Arabidopsis (Serpa et al., 2007; Tavares et al., 2014). Histone deamination could be repaired through the BER pathway, which is responsible for the repair of damaged single bases resulting from deamination, alkylation, and oxidized bases (Cimini et al., 2019). $\mathrm{H}_{2} \mathrm{~S}$ can modify the thiol group of cysteine $(-\mathrm{SH})$ in proteins into a persulfide group (-SSH) through the process of $S$-sulfhydration, which is considered as the protective mechanism for proteins against oxidative damage (Aroca et al., 2018). Cysteine residues of proteins can be modified through both $S$-nitrosation by $\mathrm{NO}$ and $S$-sulfhydration by $\mathrm{H}_{2} \mathrm{~S}$, suggesting that cysteine may be a hub between the physiological effects of $\mathrm{H}_{2} \mathrm{~S}$ and $\mathrm{NO}$, and the $S$-nitrosation and $S$-sulfhydration of cysteine may be interconvertible.

Moreover, studies in rats showed that pretreatment of $\mathrm{NaHS}$ attenuated Hcy-induced mitochondrial toxicity caused by excessive ROS and mito-ROS and restored ATP production and mtDNA copy numbers as well as oxygen consumption in the osteoblast (Zhai et al., 2019). NaHS significantly reduced oxidative stress and attenuated the mitochondrial damage induced by methylmercury $(\mathrm{MeHg})$, and they increased DNA and RNA content in the rat cerebral cortex (Han et al., 2017), indicating the potentially protective effects of $\mathrm{H}_{2} \mathrm{~S}$ against mitochondrial toxicity related to ROS (Zhai et al., 2019). Because of the importance of mitochondria in cells, the mechanisms of the regulation by $\mathrm{NO}$ and $\mathrm{H}_{2} \mathrm{~S}$ on mtDNA oxidative damage in plants under normal or different stresses are intriguing aspects and still need to be deeply studied. However, the current studies about the regulation by $\mathrm{NO}$ and $\mathrm{H}_{2} \mathrm{~S}$ on mtDNA oxidative damage in plants are still in their infancy, and there is still much research to be done.

\section{CONCLUSION AND PROSPECTS}

There are crosstalks among $\mathrm{H}_{2} \mathrm{~S}$, NO, and ROS in the biosynthesis and physiological effects. Both $\mathrm{H}_{2} \mathrm{~S}$ and $\mathrm{NO}$ can regulate ROS metabolism to maintain redox balance in plants. The redox imbalance causes DNA damage, which in turn 
exacerbates the imbalance in plants under normal and stress conditions. $\mathrm{H}_{2} \mathrm{~S}$ and $\mathrm{NO}$ are suggested to protect DNA against damage by indirectly scavenging or removing excessive ROS or by directly modifying the components and improving the ability of the DNA repair pathway. $\mathrm{H}_{2} \mathrm{~S}, \mathrm{NO}$, and ROS have many variants and can transform easily and quickly, which brings great difficulties in studying the details and even their inhibitors and scavengers regulating redox balance. At present, a great number of studies focus on the roles of $\mathrm{NO}$ in DNA damage repair, but the details and mechanisms that NO regulates damage repair are not clear. Compared with $\mathrm{NO}$, the research on the role of $\mathrm{H}_{2} \mathrm{~S}$ in DNA damage repair is in its infancy in plants. The damage and repair pathways of mtDNA are complicated, and the interplays among $\mathrm{NO}, \mathrm{H}_{2} \mathrm{~S}$, ROS, and mtDNA damage are also intricate. In what way and with which repair pathways do $\mathrm{H}_{2} \mathrm{~S}$ and $\mathrm{NO}$ regulate mtDNA oxidative damage in plants under normal or different stresses? Additionally, studies on whether the similar regulation of DNA damage repair by $\mathrm{NO}$ and $\mathrm{H}_{2} \mathrm{~S}$ present in other organelles, i.e., chloroplasts possessing their DNA (cpDNA) would also be meaningful. In recent years, the development of sequencing technology (including high throughput sequencing and single-cell sequencing) offers a fast and cost-effective method for sequencing the whole mtDNA genome (Grabherr et al., 2011; Sloan, 2013). The exploitation of universal and conserved mitochondrial primers (Duminil, 2014; Pereira et al., 2018), combined with opportunities offered by the availability

\section{REFERENCES}

Alber, N. A., Sivanesan, H., and Vanlerberghe, G. C. (2017). The occurrence and control of nitric oxide generation by the plant mitochondrial electron transport chain. Plant Cell Environ. 40, 1074-1085. doi: 10.1111/pce.12884

Alencar, R. R., Batalha, C. M. P. F., Freire, T. S., and de Souza-Pinto, N. C. (2019). Enzymology of mitochondrial DNA repair. Enzymes 45, 257-287. doi: 10.1016/ bs.enz.2019.06.002

Amooaghaie, R., Zangene-madar, F., and Enteshari, S. (2017). Role of two-sided crosstalk between $\mathrm{NO}$ and $\mathrm{H}_{2} \mathrm{~S}$ on improvement of mineral homeostasis and antioxidative defense in Sesamum indicum under lead stress. Ecotoxicol. Environ. Safety 139, 210-218. doi: 10.1016/j.ecoenv.2017.01.037

Anderson, A. P., Luo, X., Russell, W., and Yin, Y. W. (2019). Oxidative damage diminishes mitochondrial DNA polymerase replication fidelity. Nucleic Acids Res. 48, 817-829. doi: 10.1093/nar/gkz1018

Arimura, S.-I., Ayabe, H., Sugaya, H., Okuno, M., Tamura, Y., Tsuruta, Y., et al. (2020). Targeted gene disruption of ATP synthases 6-1 and 6-2 in the mitochondrial genome of Arabidopsis thaliana by mitoTALENs. Plant J. 104, 1459-1471. doi: 10.1111/tpj.15041

Aroca, A., Gotor, C., and Romero, L. C. (2018). Hydrogen sulfide signaling in plants: emerging roles of protein persulfidation. Front. Plant Sci. 9:369. doi: $10.3389 /$ fpls.2018.01369

Astier, J., Gross, I., and Durner, J. (2018). Nitric oxide production in plants: an update. J. Exp. Bot. 69, 3401-3411. doi: 10.1093/jxb/erx420

Ausma, T., and De Kok, L. J. (2019). Atmospheric $\mathrm{H}_{2} \mathrm{~S}$ : impact on plant functioning. Front. Plant Sci. 10:743. doi: 10.3389/fpls.2019.00743

Bensen, R. J., and Warner, H. R. (1987). The partial purification and characterization of nuclear and mitochondrial uracil-DNA glycosylase activities from Zea mays seedlings. Plant Physiol. 83, 149-154. doi: 10.1104/pp.83.1.149

Bhuyan, M. H. M. B., Hasanuzzaman, M., Parvin, K., Mohsin, S. M., Al Mahmud, J., Nahar, K., et al. (2020). Nitric oxide and hydrogen sulfide: two intimate collaborators regulating plant defense against abiotic stress. Plant Growth Regul. 90, 409-424. doi: 10.1007/s10725-020-00594-4 of complete mtDNA sequence in plant species, facilitate the mtDNA-based molecular studies. Moreover, the emergence of mitochondrial genome editing technology (RNA-free DddAderived cytosine base editors and mitoTALENs) enables the study of mitochondrial gene functions to be carried out in-depth (Kazama et al., 2019; Arimura et al., 2020; Mok et al., 2020). Technological developments may provide the details of mtDNA damage and the roles of $\mathrm{NO}, \mathrm{H}_{2} \mathrm{~S}$, and ROS in regulating the repair pathways of mtDNA damage in response to stress in plants as well. More advanced instruments and analytical methods are also needed to study the temporal and spatial changes of $\mathrm{NO}, \mathrm{H}_{2} \mathrm{~S}$, and ROS in plants, but there is still a long way to go.

\section{AUTHOR CONTRIBUTIONS}

DH and GJ collected the references and completed the first draft. LZ and CC revised the manuscript. SZ designed the framework and edited the manuscript. All authors contributed to the article and approved the submitted version.

\section{FUNDING}

This work was supported by the National Natural Science Foundation of China (No. 32071808).

Birke, H., Hildebrandt, T. M., Wirtz, M., and Hell, R. (2015). Sulfide detoxification in plant mitochondria. Methods Enzymol. 555, 271-286. doi: 10.1016/bs.mie. 2014.11.027

Blanc, R. S., and Richard, S. (2017). Arginine methylation: the coming of age. Mole. Cell 65, 8-24. doi: 10.1016/j.molcel.2016.11.003

Boesch, P., Ibrahim, N., Paulus, F., Cosset, A., Tarasenko, V., and Dietrich, A. (2009). Plant mitochondria possess a short-patch base excision DNA repair pathway. Nucleic Acids Res. 37, 5690-5700. doi: 10.1093/nar/gkp606

Brouquisse, R. (2019). Multifaceted roles of nitric oxide in plants. J. Exp. Bot. 70, 4319-4322. doi: 10.1093/jxb/erz352

Chaki, M., Shekariesfahlan, A., Ageeva, A., Mengel, A., von Toerne, C., Durner, J., et al. (2015). Identification of nuclear target proteins for $S$-nitrosylation in pathogen-treated Arabidopsis thaliana cell cultures. Plant Sci. 238, 115-126. doi: 10.1016/j.plantsci.2015.06.011

Chevigny, N., Schatz-Daas, D., Lotfi, F., and Gualberto, J. M. (2020). DNA repair and the stability of the plant mitochondrial genome. Int. J. Mole. Sci. 21:328. doi: 10.3390/ijms21010328

Chew, O., Whelan, J., and Millar, A. H. (2003). Molecular definition of the ascorbate-glutathione cycle in Arabidopsis mitochondria reveals dual targeting of antioxidant defenses in plants. J. Biol. Chem. 278, 46869-46877. doi: 10.1074/ jbc.M307525200

Cimini, S., Gualtieri, C., Macovei, A., Balestrazzi, A., De Gara, L., and Locato, V. (2019). Redox balance-DDR-miRNA triangle: relevance in genome stability and stress responses in plants. Front. Plant Sci. 10:989. doi: 10.3389/fpls.2019.00 989

Corpas, F. J. (2019a). Hydrogen sulfide: a new warrior against abiotic stress. Trends Plant Sci. 24, 983-988. doi: 10.1016/j.tplants.2019.08.003

Corpas, F. J. (2019b). Nitric oxide and hydrogen sulfide in higher plants under physiological and stress conditions. Antioxidants 8:457. doi: 10.3390/ antiox 8100457

Corpas, F. J., and Barroso, J. B. (2013). Nitro-oxidative stress vs oxidative or nitrosative stress in higher plants. New Phytol. 199, 633-635. doi: 10.1111/nph. 12380 
Corpas, F. J., González-Gordo, S., Cañas, A., and Palma, J. M. (2019). Nitric oxide and hydrogen sulfide in plants: which comes first? J. Exp. Bot. 70, 4391-4404. doi: $10.1093 /$ jxb/erz031

Cvetkovska, M., and Vanlerberghe, G. C. (2012). Alternative oxidase modulates leaf mitochondrial concentrations of superoxide and nitric oxide. New Phytol. 195, 32-39. doi: 10.1111/j.1469-8137.2012.04166.x

da Silva, C. J., Batista Fontes, E. P., and Modolo, L. V. (2017). Salinity-induced accumulation of endogenous $\mathrm{H}_{2} \mathrm{~S}$ and $\mathrm{NO}$ is associated with modulation of the antioxidant and redox defense systems in Nicotiana tabacum L. cv. Havana. Plant Sci. 256, 148-159. doi: 10.1016/j.plantsci.2016.12.011

Dew, T. P., Day, A. J., and Morgan, M. R. A. (2005). Xanthine oxidase activity in vitro: effects of food extracts and components. J. Agricult. Food Chem. 53, 6510-6515. doi: 10.1021/jf050716j

D’Imprima, E., Mills, D. J., Parey, K., Brandt, U., Kühlbrandt, W., Zickermann, V., et al. (2016). Cryo-EM structure of respiratory complex I reveals a link to mitochondrial sulfur metabolism. Biochim. Biophys. Acta 1857, 1935-1942. doi: 10.1016/j.bbabio.2016.09.014

Duminil, J. (2014). Mitochondrial genome and plant taxonomy. Methods Mole. Biol. 1115, 121-140. doi: 10.1007/978-1-62703-767-9_6

Ederli, L., Morettini, R., Borgogni, A., Wasternack, C., Miersch, O., Reale, L., et al. (2006). Interaction between nitric oxide and ethylene in the induction of alternative oxidase in ozone-treated tobacco plants. Plant Physiol. 142, 595-608. doi: $10.1104 /$ pp.106.085472

Eto, K., and Kimura, H. (2002). The production of hydrogen sulfide is regulated by testosterone and $S$-adenosyl-1-methionine in mouse brain. J. $f$ Neurochem. 83 , 80-86. doi: 10.1046/j.1471-4159.2002.01097.x

Fernández-Moreno, M., Tamayo, M., Soto-Hermida, A., Mosquera, A., Oreiro, N., Fernández-López, C., et al. (2011). mtDNA haplogroup J modulates telomere length and nitric oxide production. BMC Muscul. Disor. 12:283. doi: 10.1186/ 1471-2474-12-283

Ferrando, B., Furlanetto, A. L. D. M., Gredilla, R., Havelund, J. F., Hebelstrup, K. H., Møller, I. M., et al. (2019). DNA repair in plant mitochondria - a complete base excision repair pathway in potato tuber mitochondria. Physiol. Plant. 166, 494-512. doi: 10.1111/ppl.12801

Filipovic, M. R., and Jovanovic, V. M. (2017). More than just an intermediate: hydrogen sulfide signalling in plants. J. Exp. Bot. 68, 4733-4736. doi: 10.1093/ jxb/erx352

Filipovic, M. R., Zivanovic, J., Alvarez, B., and Banerjee, R. (2018). Chemical biology of $\mathrm{H}_{2} \mathrm{~S}$ signaling through persulfidation. Chem. Rev. 118, 1253-1337. doi: 10.1021/acs.chemrev.7b00205

Fluhr, R. (2009). "Reactive oxygen-generating NADPH oxidases in plants," in Reactive Oxygen Species in Plant Signaling, eds L. A. Rio and A. Puppo (Heidelberg: Springer Berlin Heidelberg), 1-23. doi: 10.1007/978-3-642-00390$5 \_1$

Foreman, J., Demidchik, V., Bothwell, J. H. F., Mylona, P., Miedema, H., Torres, M. A., et al. (2003). Reactive oxygen species produced by NADPH oxidase regulate plant cell growth. Nature 422, 442-446. doi: 10.1038/nature01485

Forman, H. J., Maiorino, M., and Ursini, F. (2010). Signaling functions of reactive oxygen species. Biochemistry 49, 835-842. doi: 10.1021/bi9020378

Geng, B., Huang, D., and Zhu, S. (2019). Regulation of hydrogen sulfide metabolism by nitric oxide inhibitors and the quality of peaches during cold storage. Antioxidants 8:401. doi: 10.3390/antiox8090401

González-Gordo, S., Palma, J. M., and Corpas, F. J. (2020). Appraisal of $\mathrm{H}_{2} \mathrm{~S}$ metabolism in Arabidopsis thaliana: in silico analysis at the subcellular level. Plant Physiol. Biochem. 155, 579-588. doi: 10.1016/j.plaphy.2020.08.014

Gonzalez-Hunt, C. P., Wadhwa, M., and Sanders, L. H. (2018). DNA damage by oxidative stress: measurement strategies for two genomes. Curr. Opin. Toxicol. 7, 87-94. doi: 10.1016/j.cotox.2017.11.001

Gotor, C., García, I., Aroca, Á, Laureano-Marín, A. M., Arenas-Alfonseca, L., Jurado-Flores, A., et al. (2019). Signaling by hydrogen sulfide and cyanide through post-translational modification. J. Exp. Bot. 70, 4251-4265. doi: 10. 1093/jxb/erz225

Grabherr, M. G., Haas, B. J., Yassour, M., Levin, J. Z., Thompson, D. A., Amit, I., et al. (2011). Full-length transcriptome assembly from RNA-Seq data without a reference genome. Nat. Biotechnol. 29, 644-652. doi: 10.1038/nbt.1883

Guo, H., Xiao, T., Zhou, H., Xie, Y., and Shen, W. (2016). Hydrogen sulfide: a versatile regulator of environmental stress in plants. Acta Physiol. Plant. 38:16. doi: $10.1007 / \mathrm{s} 11738-015-2038-\mathrm{x}$
Gupta, K. J., Hancock, J. T., Petrivalsky, M., Kolbert, Z., Lindermayr, C., Durner, J., et al. (2020). Recommendations on terminology and experimental best practice associated with plant nitric oxide research. New Phytol. 225, 1828-1834. doi: 10.1111/nph.16157

Gupta, K. J., Kumari, A., Florez-Sarasa, I., Fernie, A. R., and Igamberdiev, A. U. (2018). Interaction of nitric oxide with the components of the plant mitochondrial electron transport chain. J. Exp. Bot. 69, 3413-3424. doi: 10.1093/ jxb/ery119

Han, J., Yang, X., Chen, X., Li, Z., Fang, M., Bai, B., et al. (2017). Hydrogen sulfide may attenuate methylmercury-induced neurotoxicity via mitochondrial preservation. Chem.-Biol. Int. 263, 66-73. doi: 10.1016/j.cbi.2016.12.020

Hancock, J. T. (2017). Harnessing evolutionary toxins for signaling: reactive oxygen species, nitric oxide and hydrogen sulfide in plant cell regulation. Front. Plant Sci. 8:189. doi: 10.3389/fpls.2017.00189

Hancock, J. T. (2019). Hydrogen sulfide and environmental stresses. Environ. Exp. Bot. 161, 50-56. doi: 10.1016/j.envexpbot.2018.08.034

Hancock, J. T., and Whiteman, M. (2014). Hydrogen sulfide and cell signaling: team player or referee? Plant Physiol. Biochem. 78, 37-42. doi: 10.1016/j.plaphy. 2014.02.012

Hancock, J. T., and Whiteman, M. (2016). Hydrogen sulfide signaling: interactions with nitric oxide and reactive oxygen species. Anna. N. Y. Acad. Sci. 1365, 5-14. doi: $10.1111 /$ nyas. 12733

Hu, K.-D., Zhang, X.-Y., Yao, G.-F., Rong, Y.-L., Ding, C., Tang, J., et al. (2020). A nuclear-localized cysteine desulfhydrase plays a role in fruit ripening in tomato. Horticult. Res. 7:211. doi: 10.1038/s41438-020-00439-1

Huang, H., Ullah, F., Zhou, D.-X., Yi, M., and Zhao, Y. (2019). Mechanisms of ROS regulation of plant development and stress responses. Front. Plant Sci. 10:80. doi: 10.3389/fpls.2019.00800

Huang, X., von Rad, U., and Durner, J. (2002). Nitric oxide induces transcriptional activation of the nitric oxide-tolerant alternative oxidase in Arabidopsis suspension cells. Planta 215, 914-923. doi: 10.1007/s00425-002-0828-z

Hussain, A., Mun, B.-G., Imran, Q. M., Lee, S.-U., Adamu, T. A., Shahid, M., et al. (2016). Nitric oxide mediated transcriptome profiling reveals activation of multiple regulatory pathways in Arabidopsis thaliana. Front. Plant Sci. 7:975. doi: $10.3389 /$ fpls.2016.00975

Iriyoda, T. M. V., Stadtlober, N., Lozovoy, M. A. B., Delongui, F., Costa, N. T., Reiche, E. M. V., et al. (2017). Reduction of nitric oxide and DNA/RNA oxidation products are associated with active disease in systemic lupus erythematosus patients. Lupus 26, 1106-1111. doi: 10.1177/096120331769 2436

Jia, H., Hao, L., Guo, X., Liu, S., Yan, Y., and Guo, X. (2016). A Raf-like MAPKKK gene, GhRaf19, negatively regulates tolerance to drought and salt and positively regulates resistance to cold stress by modulating reactive oxygen species in cotton. Plant Sci. 252, 267-281. doi: 10.1016/j.plantsci.2016.07.014

Jiang, D., Wei, S., Chen, F., Zhang, Y., and Li, J. (2017). TET3-mediated DNA oxidation promotes ATR-dependent DNA damage response. EMBO Rep. 18, 781-796. doi: 10.15252/embr.201643179

Jiao, J., Sun, L., Zhou, B., Gao, Z., Hao, Y., Zhu, X., et al. (2014). Hydrogen peroxide production and mitochondrial dysfunction contribute to the fusaric acid-induced programmed cell death in tobacco cells. J. Plant Physiol. 171, 1197-1203. doi: 10.1016/j.jplph.2014.03.015

Jimenez, A., Hernandez, J. A., del Rio, L. A., and Sevilla, F. (1997). Evidence for the presence of the ascorbate-glutathione cycle in mitochondria and peroxisomes of pea leaves. Plant Physiol. 114, 275-284. doi: 10.1104/pp.114.1.275

Jin, Z., Wang, Z., Yang, G., and Pei, Y. (2018). Diversity of hydrogen sulfide concentration in plant: a little spark to start a prairie fire. Sci. Bull. 63, 13141316. doi: 10.1016/j.scib.2018.09.012

Jones, L. E. Jr., Ying, L., Hofseth, A. B., Jelezcova, E., Sobol, R. W., Ambs, S., et al. (2009). Differential effects of reactive nitrogen species on DNA base excision repair initiated by the alkyladenine DNA glycosylase. Carcinogenesis 30, 2123-2129. doi: 10.1093/carcin/bgp256

Katsuya-Gaviria, K., Caro, E., Carrillo-Barral, N., and Iglesias-Fernández, R. (2020). Reactive oxygen species (ROS) and nucleic acid modifications during seed dormancy. Plants 9:679. doi: 10.3390/plants9060679

Kazama, T., Okuno, M., Watari, Y., Yanase, S., Koizuka, C., Tsuruta, Y., et al. (2019). Curing cytoplasmic male sterility via TALEN-mediated mitochondrial genome editing. Nat. Plants 5, 722-730. doi: 10.1038/s41477-0190459-z 
Kobaisi, F., Fayyad, N., Rezvani, H. R., Fayyad-Kazan, M., Sulpice, E., Badran, B., et al. (2019). Signaling pathways, chemical and biological modulators of nucleotide excision repair: the faithful shield against UV genotoxicity. Oxidat. Med. Cell. Long. 2019:4654206. doi: 10.1155/2019/4654206

Kolbert, Z., Barroso, J. B., Brouquisse, R., Corpas, F. J., Gupta, K. J., Lindermayr, C., et al. (2019). A forty year journey: the generation and roles of NO in plants. Nitr. Oxide 93, 53-70. doi: 10.1016/j.niox.2019.09.006

Krokan, H. E., Standal, R., and Slupphaug, G. (1997). DNA glycosylases in the base excision repair of DNA. Biochem. J. 325, 1-16. doi: 10.1042/bj3250001

Kumar, R. M. S., Wang, Y., Zhang, X., Cheng, H., Sun, L., He, S., et al. (2020). Redox components: key regulators of epigenetic modifications in plants. Int. J. Mole. Sci. 21:1419. doi: 10.3390/ijms21041419

Kwak, J. M., Mori, I. C., Pei, Z.-M., Leonhardt, N., Torres, M. A., Dangl, J. L., et al. (2003). NADPH oxidase AtrbohD and AtrbohF genes function in ROSdependent ABA signaling in Arabidopsis. EMBO J. 22, 2623-2633. doi: 10.1093/ emboj/cdg277

Lans, H., Hoeijmakers, J. H. J., Vermeulen, W., and Marteijn, J. A. (2019). The DNA damage response to transcription stress. Nat. Rev. Mole. Cell Biol. 20, 766-784. doi: 10.1038/s41580-019-0169-4

Law, J. A., and Jacobsen, S. E. (2009). Dynamic DNA methylation. Science 323:1568. doi: 10.1126/science. 1172782

Liang, Y., Zheng, P., Li, S., Li, K., and Xu, H. (2018). Nitrate reductase-dependent $\mathrm{NO}$ production is involved in $\mathrm{H}_{2} \mathrm{~S}$-induced nitrate stress tolerance in tomato via activation of antioxidant enzymes. Sci. Horticult. 229, 207-214. doi: 10.1016/j. scienta.2017.10.044

Lin, X., Yang, R., Dou, Y., Zhang, W., Du, H., Zhu, L., et al. (2020). Transcriptome analysis reveals delaying of the ripening and cell-wall degradation of kiwifruit by hydrogen sulfide. J. Sci. Food Agricult. 100, 2280-2287. doi: 10.1002/jsfa. 10260

Lindermayr, C., Saalbach, G., and Durner, J. (2005). Proteomic identification of S-nitrosylated proteins in Arabidopsis. Plant Physiol. 137, 921-930. doi: 10. 1104/pp.104.058719

Liu, H., Ma, L. L., Yang, X. R., Zhang, L., Zeng, X., Xie, S. P., et al. (2017). Integrative analysis of DNA methylation, mRNAs, and small RNAs during maize embryo dedifferentiation. BMC Plant Biol. 17:105. doi: 10.1186/s12870-017-1055-x

Liu, Y. G., Shi, L., Ye, N. H., Liu, R., Jia, W. S., and Zhang, J. H. (2009). Nitric oxideinduced rapid decrease of abscisic acid concentration is required in breaking seed dormancy in Arabidopsis. New Phytol. 183, 1030-1042. doi: 10.1111/j. 1469-8137.2009.02899.x

Liu, Y., Lei, X.-Y., Chen, L.-F., Bian, Y.-B., Yang, H., Ibrahim, S. A., et al. (2015). A novel cysteine desulfurase influencing organosulfur compounds in Lentinula edodes. Scient. Rep. 5:10047. doi: 10.1038/srep 10047

Martínez-Redondo, D., Marcuello, A., Casajús, J. A., Ara, I., Dahmani, Y., Montoya, J., et al. (2010). Human mitochondrial haplogroup $\mathrm{H}$ : the highest $\mathrm{VO}_{2 \max }$ consumer - is it a paradox? Mitochondrion 10, 102-107. doi: 10.1016/j. mito.2009.11.005

Mengel, A., Ageeva, A., Georgii, E., Bernhardt, J., Wu, K., Durner, J., et al. (2017). Nitric oxide modulates histone acetylation at stress genes by inhibition of histone deacetylases. Plant Physiol. 173, 1434-1452. doi: 10.1104/pp.16. 01734

Merchant, K., Chen, H., Gonzalez, T. C., Keefer, L. K., and Shaw, B. R. (1996). Deamination of single-stranded DNA cytosine residues in aerobic nitric oxide solution at micromolar total NO exposures. Chem. Res. Toxicol. 9, 891-896. doi: $10.1021 /$ tx950102g

Michalak, M., Barciszewska, M. Z., Barciszewski, J., Plitta, B. P., and Chmielarz, P. (2013). Global changes in DNA methylation in seeds and seedlings of Pyrus communis after seed desiccation and storage. PLoS One 8:e70693. doi: 10.1371/ journal.pone.0070693

Millar, A. H., and Day, D. A. (1996). Nitric oxide inhibits the cytochrome oxidase but not the alternative oxidase of plant mitochondria. FEBS Lett. 398, 155-158. doi: 10.1016/S0014-5793(96)01230-6

Mok, B. Y., de Moraes, M. H., Zeng, J., Bosch, D. E., Kotrys, A. V., Raguram, A., et al. (2020). A bacterial cytidine deaminase toxin enables CRISPR-free mitochondrial base editing. Nature 583, 631-637. doi: 10.1038/s41586-0202477-4

Moore, A. L., and Siedow, J. N. (1991). The regulation and nature of the cyanideresistant alternative oxidase of plant mitochondria. Biochim. Biophys. Acta 1059, 121-140. doi: 10.1016/S0005-2728(05)80197-5
Muñoz-Vargas, M. A., González-Gordo, S., Cañas, A., López-Jaramillo, J., Palma, J. M., and Corpas, F. J. (2018). Endogenous hydrogen sulfide $\left(\mathrm{H}_{2} \mathrm{~S}\right)$ is upregulated during sweet pepper (Capsicum annuum L.) fruit ripening. In vitro analysis shows that NADP-dependent isocitrate dehydrogenase (ICDH) activity is inhibited by $\mathrm{H}_{2} \mathrm{~S}$ and NO. Nitr. Oxide 81, 36-45. doi: 10.1016/j.niox.2018.10. 002

Muñoz-Vargas, M. A., González-Gordo, S., Palma, J. M., and Corpas, F. J. (2020). Inhibition of NADP-malic enzyme activity by $\mathrm{H}_{2} \mathrm{~S}$ and $\mathrm{NO}$ in sweet pepper (Capsicum annuum L.) fruits. Physiol. Plant. 168, 278-288. doi: 10.1111/ppl. 13000

Nagaraja, S. S., Subramanian, U., and Nagarajan, D. (2021). Radiation-induced H3K9 methylation on E-cadherin promoter mediated by ROS/Snail axis : role of G9a signaling during lung epithelial-mesenchymal transition. Toxicol. Vitro 70:105037. doi: 10.1016/j.tiv.2020.105037

Nesci, S., Trombetti, F., Ventrella, V., and Pagliarani, A. (2017). Post-translational modifications of the mitochondrial $\mathrm{F}_{1} \mathrm{~F}_{\mathrm{O}}$-ATPase. Biochim. Biophys. Acta 1861, 2902-2912. doi: 10.1016/j.bbagen.2017.08.007

Noctor, G., Mhamdi, A., Chaouch, S., Han, Y., Neukermans, J., Marquez-Garcia, B., et al. (2012). Glutathione in plants: an integrated overview. Plant Cell Environ. 35, 454-484. doi: 10.1111/j.1365-3040.2011.02400.x

Olson, K. R. (2018). $\mathrm{H}_{2} \mathrm{~S}$ and polysulfide metabolism: Conventional and unconventional pathways. Biochem. Pharmacol. 149, 77-90. doi: 10.1016/j.bcp. 2017.12.010

Ou, X., Zhuang, T., Yin, W., Miao, Y., Wang, B., Zhang, Y., et al. (2015). DNA methylation changes induced in rice by exposure to high concentrations of the nitric oxide modulator, sodium nitroprusside. Plant Mole. Biol. Rep. 33, 1428-1440. doi: 10.1007/s11105-014-0843-9

Pegg, A. E. (2000). Repair of $\mathrm{O}^{6}$-alkylguanine by alkyltransferases. Mutat. Res. Rev. Mutat. Res. 462, 83-100. doi: 10.1016/S1383-5742(00)00017-X

Peng, R., Bian, Z., Zhou, L., Cheng, W., Hai, N., Yang, C., et al. (2016). Hydrogen sulfide enhances nitric oxide-induced tolerance of hypoxia in maize (Zea mays L.). Plant Cell Rep. 35, 2325-2340. doi: 10.1007/s00299-016-2037-4

Pereira, V., Longobardi, A., and Børsting, C. (2018). Sequencing of mitochondrial genomes using the precision ID mtDNA whole genome panel. Electrophoresis 39, 2766-2775. doi: 10.1002/elps.201800088

Piantadosi, C. A. (2020). Mitochondrial DNA, oxidants, and innate immunity. Free Rad. Biol. Med. 152, 455-461. doi: 10.1016/j.freeradbiomed.2020.01.013

Poetsch, A. R. (2020). The genomics of oxidative DNA damage, repair, and resulting mutagenesis. Computat. Struct. Biotechnol. J. 18, 207-219. doi: 10. 1016/j.csbj.2019.12.013

Porrini, C., Ramarao, N., and Tran, S.-L. (2020). Dr. NO and Mr. Toxic the versatile role of nitric oxide. Biol. Chem. 401:547. doi: 10.1515/hsz-20190368

Qi, Q., Guo, Z., Liang, Y., Li, K., and Xu, H. (2019). Hydrogen sulfide alleviates oxidative damage under excess nitrate stress through MAPK/NO signaling in cucumber. Plant Physiol. Biochem. 135, 1-8. doi: 10.1016/j.plaphy.2018. 11.017

Rahikainen, M., Alegre, S., Trotta, A., Pascual, J., and Kangasjärvi, S. (2018). Transmethylation reactions in plants: focus on the activated methyl cycle. Physiol. Plant. 162, 162-176. doi: 10.1111/ppl.12619

Serpa, V., Vernal, J., Lamattina, L., Grotewold, E., Cassia, R., and Terenzi, H. (2007). Inhibition of AtMYB2 DNA-binding by nitric oxide involves cysteine S-nitrosylation. Biochem. Biophys. Res. Commun. 361, 1048-1053. doi: 10.1016/ j.bbrc.2007.07.133

Sloan, D. B. (2013). One ring to rule them all? genome sequencing provides new insights into the 'master circle' model of plant mitochondrial DNA structure. New Phytol. 200, 978-985. doi: 10.1111/nph.12395

Tavares, C. P., Vernal, J., Delena, R. A., Lamattina, L., Cassia, R., and Terenzi, H. (2014). S-nitrosylation influences the structure and DNA binding activity of AtMYB30 transcription factor from Arabidopsis thaliana. Biochim. Biophys. Acta 1844, 810-817. doi: 10.1016/j.bbapap.2014.02.015

Teng, Y., Yadav, T., Duan, M., Tan, J., Xiang, Y., Gao, B., et al. (2018). ROSinduced $\mathrm{R}$ loops trigger a transcription-coupled but BRCA1/2-independent homologous recombination pathway through CSB. Nat. Commun. 9:4115. doi: 10.1038/s41467-018-06586-3

Trachootham, D., Lu, W., Ogasawara, M. A., Valle, N. R.-D., and Huang, P. (2008). Redox regulation of cell survival. Antioxid. Redox Sign,. 10, 1343-1374. doi: 10.1089/ars.2007.1957 
Van Houten, B., Santa-Gonzalez, G. A., and Camargo, M. (2018). DNA repair after oxidative stress: current challenges. Curr. Opin. Toxicol. 7, 9-16. doi: 10.1016/j.cotox.2017.10.009

Wang, C., Huang, D., Tian, W., and Zhu, S. (2021). Nitric oxide alleviates mitochondrial oxidative damage and maintains mitochondrial functions in peach fruit during cold storage. Sci. Horticult. 287:110249. doi: 10.1016/j. scienta.2021.110249

Waszczak, C., Carmody, M., and Kangasjärvi, J. (2018). Reactive oxygen species in plant signaling. Annu. Rev. Plant Biol. 69, 209-236. doi: 10.1146/annurevarplant-042817-040322

Wei, G.-Q., Zhang, W.-W., Cao, H., Yue, S.-S., Li, P., and Yang, H.-Q. (2019). Effects hydrogen sulfide on the antioxidant system and membrane stability in mitochondria of Malus hupehensis under $\mathrm{NaCl}$ stress. Biol. Plant. 63, 228-236.

$\mathrm{Wu}$, Q., and $\mathrm{Ni}, \mathrm{X}$. (2015). ROS-mediated DNA methylation pattern alterations in carcinogenesis. Curr. Drug Target. 16, 13-19. doi: $10.2174 / 1389450116666150113121054$

Wu, X., Li, G., and Xie, R. (2018). Decoding the role of TET family dioxygenases in lineage specification. Epigenet. Chrom. 11:58. doi: 10.1186/s13072-018-0228-7

Wynn, E., Purfeerst, E., and Christensen, A. (2020). Mitochondrial DNA repair in an Arabidopsis thaliana uracil N-glycosylase mutant. Plants 9:261. doi: 10.3390/ plants9020261

Xu, W., Liu, L., Smith, G. C. M., and Charles, l. G (2000). Nitric oxide upregulates expression of DNA-PKcs to protect cells from DNA-damaging anti-tumour agents. Nat. Cell Biol. 2, 339-345. doi: 10.1038/35014028

Yagci, S., Yildirim, E., Yildirim, N., Shams, M., and Agar, G. (2019). Nitric oxide alleviates the effects of copper-induced DNA methylation, genomic instability, LTR retrotransposon polymorphism and enzyme activity in lettuce. Plant Physiol. Rep. 24, 289-295. doi: 10.1007/s40502-01900455-x

Yi, C., and He, C. (2013). DNA repair by reversal of DNA damage. Cold Spring Harbor Perspect. Biol. 5:a012575. doi: 10.1101/cshperspect.a0 12575

Yu, S.-X., Feng, Q.-N., Xie, H.-T., Li, S., and Zhang, Y. (2017). Reactive oxygen species mediate tapetal programmed cell death in tobacco and tomato. BMC Plant Biol. 17:76. doi: 10.1186/s12870-017-1025-3

Zhai, Y., Behera, J., Tyagi, S. C., and Tyagi, N. (2019). Hydrogen sulfide attenuates homocysteine-induced osteoblast dysfunction by inhibiting mitochondrial toxicity. J. Cell. Physiol. 234, 18602-18614. doi: 10.1002/jcp.28498
Zhang, H., Lang, Z., and Zhu, J.-K. (2018). Dynamics and function of DNA methylation in plants. Nat. Rev. Mole. Cell Biol. 19, 489-506. doi: 10.1038/ s41580-018-0016-Z

Zhang, L., Pei, Y., Wang, H., Jin, Z., Liu, Z., Qiao, Z., et al. (2015). Hydrogen sulfide alleviates cadmium-induced cell death through restraining ROS accumulation in roots of Brassica rapa L. ssp. pekinensis. Oxidat. Med. Cell. Long. 2015:804603. doi: $10.1155 / 2015 / 804603$

Zhang, M., Wang, L., and Zhong, D. (2017). Photolyase: dynamics and mechanisms of repair of sun-induced DNA damage. Photochem. Photobiol. 93, 78-92. doi: 10.1111/php.12695

Zhang, P., Luo, Q., Wang, R., and Xu, J. (2017). Hydrogen sulfide toxicity inhibits primary root growth through the ROS-NO pathway. Scient. Rep. 7:868. doi: 10.1038/s41598-017-01046-2

Zheng, M., Lin, J., Liu, X., Chu, W., Li, J., Gao, Y., et al. (2021). Histone acetyltransferase TaHAG1 acts as a crucial regulator to strengthen salt tolerance of hexaploid wheat. Plant Physiol. doi: 10.1093/plphys/kiab187 [Epub Online ahead of print]

Zhu, L., Wang, W., Shi, J., Zhang, W., Shen, Y., Du, H., et al. (2014). Hydrogen sulfide extends the postharvest life and enhances antioxidant activity of kiwifruit during storage. J. Sci. Food Agricult. 94, 2699-2704. doi: 10.1002/jsfa. 6613

Conflict of Interest: The authors declare that the research was conducted in the absence of any commercial or financial relationships that could be construed as a potential conflict of interest.

Publisher's Note: All claims expressed in this article are solely those of the authors and do not necessarily represent those of their affiliated organizations, or those of the publisher, the editors and the reviewers. Any product that may be evaluated in this article, or claim that may be made by its manufacturer, is not guaranteed or endorsed by the publisher.

Copyright (c) 2021 Huang, Jing, Zhang, Chen and Zhu. This is an open-access article distributed under the terms of the Creative Commons Attribution License (CC BY). The use, distribution or reproduction in other forums is permitted, provided the original author(s) and the copyright owner(s) are credited and that the original publication in this journal is cited, in accordance with accepted academic practice. No use, distribution or reproduction is permitted which does not comply with these terms. 